\title{
RESEARCH
}

Open Access

\section{Predictors of mortality among HIV exposed infants at University of Gondar Comprehensive Specialized Hospital, Northwest Ethiopia}

\author{
Chalachew Adugna Wubneh $^{1^{*}}$ (D) Aklilu Endalamaw ${ }^{2}$ and Nigusie Birhan Tebeje ${ }^{3}$
}

\begin{abstract}
Background: In the era of highly active antiretroviral therapy, vertical HIV transmission has been decreased. This may increase fertility desire of HIV infected women and an increasing number of HIV exposed infants as a result. A high probability of mortality among HIV exposed infants was reported across different countries. However, few studies are found on mortality of HIV exposed infants, in particular, no study was conducted before in the current study area.

Methods: Institution based retrospective cohort study from July 2013 to December 2017 was conducted. A total of 408 HIV exposed children were selected through simple random sampling technique. Data were extracted from registration book by using data extraction tool, which is adapted from the Ethiopian Federal Ministry of Health HIV exposed infant follow-up form. Kaplan-Meier survival curve was used to show the probability of mortality rate. Bivariable and multivariable cox regression models were used to identify predictors of mortality.

Results: Overall mortality rate was found to be 8.88 (95\% Cl: 6.36-12.36) per 100 child-year. Infant with death of at least one parent ( $A H R=3.32 ; 95 \% \mathrm{Cl}: 1.503-7.32$ ), non-exclusive breastfeeding ( $A H R=0.10 ; 95 \%$ $\mathrm{Cl}: 0.037-0.302)$, growth failure (AHR $=2.9 ; 95 \% \mathrm{Cl}: 1.09-8.09)$, presence of sign and symptom of HIV infection (AHR $=2.99 ; 95 \% \mathrm{Cl}: 1.33-6.74)$, and low birth weight $(\mathrm{AHR}=2.6 ; 95 \% \mathrm{Cl}: 1.007-6.78)$ were found to be predictors of infant mortality.

Conclusions: Mortality of HIV exposed infants was high in Ethiopia. Prevention of the occurrence of HIV infection symptom, growth failure, and low birth weight is essential and further treat early whenever they occurred. Still, behavioral change interventions on mother who practice non-exclusive breastfeeding are indicated. Especial care for orphan infants is required due to their nature of vulnerability to varieties of health problem.
\end{abstract}

Keywords: HIV exposed infant, Mortality, Predictors, Ethiopia

\footnotetext{
* Correspondence: mekidem21@gmail.com

${ }^{1}$ Department of Pediatrics and Child Health Nursing, School of Nursing,

College of Medicine and Health Science, University of Gondar, Gondar,

Ethiopia

Full list of author information is available at the end of the article
}

(c) The Author(s). 2019 Open Access This article is distributed under the terms of the Creative Commons Attribution 4.0 International License (http://creativecommons.org/licenses/by/4.0/), which permits unrestricted use, distribution, and reproduction in any medium, provided you give appropriate credit to the original author(s) and the source, provide a link to the Creative Commons license, and indicate if changes were made. The Creative Commons Public Domain Dedication waiver (http://creativecommons.org/publicdomain/zero/1.0/) applies to the data made available in this article, unless otherwise stated. 


\section{Background}

Based on the Joint United Nations Program on HIV/ AIDS (UNAIDS) report in 2018, 36.9 million people living with Human Immunodeficiency Virus (HIV). Of which, more than $50 \%$ were women and $90 \%$ of HIV positive pregnant women live in sub-Saharan Africa [1]. According to the global plan towards the elimination of new HIV infections among children mother to child HIV transmission has been reduced by $60 \%$ and the number of ADIS related child death was 49,000 as a referee of 2015 report [2]. It shows child mortality continued to be a persistent global problem. In 2015, an estimated 1.2 million babies were born from HIVpositive mothers $[3,4]$. Those children born from HIV positive mothers are at higher risk of death [5]. Infant health is one of the indicators of countries developmental progress.

Consequently, at the international and national level, different strategies have been implemented to reduce mortality of children born from HIV positive mother. Notably, the World Health Organization (WHO) four prongs Prevention of Mother-to-Child Transmission (PMTCT) of HIV approach considered a key entry point of care for HIV positive pregnant, laboring and lactating women and their children is to be an infant mortality preventive strategy. These include primary prevention of HIV infection, prevention of unintended pregnancy among HIV positive women, prevention of HIV transmission from infected women to their children and treatment, care and support of HIV infected women, their newborn and families [6, 7]. Moreover, the Ethiopian ministry of health initiated 'option B+' PMTCT approach since 2013 [6]. This approach recommends initiating Antiretroviral Therapy (ART) for all pregnant, laboring and lactating women, improving ART coverage, test to HIV and start HAART for all HIV positive children, early diagnosis for HIV exposed infant and improving health service utilization $[6,8]$.

Despite these much of interventions, the mortality of children who born from HIV positive mother is the public health problem for African and other less developed countries [9]. The incidence of child mortality reported $5 / 1000$ person-year in India [10] and 150 per 1000 person-years in Zimbabwe [11]. It is also reported in Uganda (3.9\%) [12], Cameron (23.9\%) [13], Malawi (6.39.3\%) [14], Rwanda (4.8\%) [15], and Kenya 39\% [16].

The High mortality of infants born from HIV positive mother has been attributed to different predictors. Some of the predictors identified in the previous studies from different countries include advanced maternal disease [17], HIV infection of the child [11, 14, 18], low birth weight [14], maternal survival status [19], early and abrupt breastfeeding cessation and mixed feeding $[13,15,20]$, and prematurity [13].
In Ethiopia, there is no study done to estimate the mortality of HIV exposed infants before. Therefore, we assessed mortality and its predictors among HIV exposed infants at the University of Gondar comprehensive specialized hospital, Northwest Ethiopia.

\section{Method}

\section{Study design and period}

A retrospective cohort study from July 2013 to December 2017 at the University of Gondar Comprehensive Specialized Hospital was conducted.

\section{Study setting}

University of Gondar Comprehensive Specialized Hospital is a teaching hospital, which serves more than five million people in the catchment area. This hospital has started to provide ART for children, adult and PMTCT service for women and their child since 2005. The hospital has started a new PMTC service since 2013 which is 'option $\mathrm{B}+$ ' that recommends treating all HIV positive pregnant, laboring and lactating women and starting follow-up for newborn up to 18 months.

\section{Source and study population}

All infants less than 18 months of age who were born from HIV positive mother.

\section{Inclusion}

Infants born from HIV positive mother and have a follow-up on the study area were included.

\section{Exclusion criteria}

Infants and their mothers with incomplete baseline data were excluded.

\section{Sampling technique and procedures}

Those HIV exposed infants on follow-up have successive registration. Therefore, the number of samples was selected using the computer generated number from the database. Based on the selected child card number, child and mother-pair chart was accessed and retrieved. There were 768 HIV exposed infants' who have a follow-up from July 2013 to December 2017. By using simple random sampling technique, 423 mother-child cards were retrieved.

\section{Study variable Children variable}

Sex, birth weight, gestational age at birth, growth pattern, ARV prophylaxis, adherence to cotrimoxazole preventive therapy (CPT), the presence of suggestive sign and symptom of HIV and infant feeding type. 


\section{Parent variable}

Age, marital status, educational status, residence, number of birth for the mother and father HIV status, ANC follow up, ART staring time, baseline CD4 count, Baseline WHO clinical stage, place of delivery, mode of delivery and parent survival status.

\section{Operational definitions \\ HIV exposed infants}

Children born from HIV positive mother.

\section{Lost to follow-up}

Infants missing their appointment for more than three months.

\section{Suggestive sign and symptom of HIV infection}

The presence of at least one abnormal finding suggestive of HIV infection, which includes purulent ear discharge, pneumonia/ lower respiratory infection, persistence diarrhea, and persistence fever.

\section{Data collection tool and procedures}

Data were extracted by using data extraction tool customized from Ethiopian federal ministry of health HIV exposed infant follow-up form that is prepared in the English language. Data were collected from HIV exposed infant and mother's chart and registration book. Three BSc nurse who has PMTCT training collected the required data.

\section{Data quality control measures}

Data abstraction tool was evaluated and commented by other researchers. For its completeness, the data extraction tool was check from chart and follow-up registration book. A pretest was conducted on $10 \%$ of the sample size at the University of Gondar Comprehensive Specialized Hospital. Based on the pretest some modification on the data collection tool was made trained BSc nurses were recruited. One-day training was given to data collectors. The data collection process was closely monitored by one MSc nurse supervisor.

\section{Data processing and analysis}

Data were checked and coded and entered into EPI info version 7.2.2.6. Then, data were exported to SPSS version 20. Descriptive statistics were used to analyze the socio-demographic characteristics and proportion of mortality. Kaplan-Meier survival curve was used to see the probability of child mortality. Bivariable and multivariable Cox regression models were used to identify predictors of mortality. Those variables having $P$-value $\leq 0.2$ in the Bivariable analysis were entered into the multivariable model. The Cox proportional hazard model assumption was checked by using Schoenfeld residuals test. The adjusted hazard ratio (AHR) with a 95\% confidence interval (CI) was calculated. P-value $\leq 0.05$ was considered as statistically significant.

\section{Follow up and outcome ascertainment}

Starting from 2013 the University of Gondar compressive specialized hospital have HIV exposed child and mother cohort up to the age of 18 months. We use this cohort data retrospectively for this study. Study participants have different follow-up period and different entrance time. The mortality was reported as the death of the child starting from follow-up to the end of 18 months and as register from the follow-up form. It is difficult to relate the exact cause of death because of the quality of documentation. It is not cause specific mortality rate but death related to accident or trauma is not reported on the format.

\section{Ethical considerations}

Ethical clearance was obtained from the University of Gondar institutional ethical review committee. To maintain the confidentiality of the study participants' information and identifiers like name and medical record number was removed from the data extraction tool. Confidentiality of the information was maintained throughout the research process.

\section{Result}

Socio-demographic characteristics of the parent

A total of 408 mother-child- pairs' card have included in the study which provided a $96.4 \%$ response rate. Most of $(81.9 \%)$ of mothers were from urban. Majority $(72.5 \%)$ of mothers were married. Regarding religion, 90\% were Orthodox Christian. More than three-fourths of mothers (77\%) attended primary school level and above (Table 1).

\section{Socio-demographic and health-related characteristics of HIV exposed infants}

From the total 408 children, more than half (52\%) were male. The mean birth weight of the infants was $2.8 \mathrm{~kg}$. Majority (90.7\%) of the infants had term gestational age at birth. Majority of infants (93.9\%) were enrolled to PMTCT clinic with the age of 45 days. All of the infants had started ART prophylaxis (Nevirapine (NVP) according to the schedule and (99\%) of them had good adherence to cotrimoxazole preventive therapy (Table 2).

\section{Pregnancy, delivery, and clinical characteristics of HIV positive mothers}

Most of the mothers (94.9\%) had attended at least one antenatal care visit for the current pregnancy. Among mothers attended ANC, (90.7\%) were screened for sexually transmitted infections. Nearly $4 \%$ (3.8\%) of mothers screened for sexually transmitted infections were reactive. 
Table 1 Socio-demographic characteristics of parent at University of Gondar comprehensive specialized hospital, from July 2013-December 2017

\begin{tabular}{|c|c|c|}
\hline Characteristic of the parent & Number & Percent (\%) \\
\hline \multicolumn{3}{|l|}{ Age of mother } \\
\hline Less than 20 years & 6 & 1.5 \\
\hline 20-25 year & 65 & 15.9 \\
\hline 26-30 year & 180 & 44.1 \\
\hline 31 year and above & 157 & 38.5 \\
\hline \multicolumn{3}{|l|}{ Residence of the mother } \\
\hline Urban & 334 & 81.9 \\
\hline Rural & 74 & 18.1 \\
\hline \multicolumn{3}{|l|}{ Marital status of the mother } \\
\hline Married & 296 & 72.5 \\
\hline Unmarried & 112 & 27.5 \\
\hline \multicolumn{3}{|l|}{ Occupation of the mother } \\
\hline Government employed & 111 & 27.2 \\
\hline Non-employed & 297 & 72.8 \\
\hline \multicolumn{3}{|l|}{ Religious of the mother } \\
\hline Orthodox Christian & 367 & 90 \\
\hline Muslim & 38 & 9.3 \\
\hline Protestant & 3 & 0.7 \\
\hline \multicolumn{3}{|c|}{ Educational level of the mother } \\
\hline Unable to read and write & 94 & 23 \\
\hline Primary education & 136 & 33.3 \\
\hline Secondary education & 114 & 27.9 \\
\hline College and above & 64 & 15.7 \\
\hline \multicolumn{3}{|l|}{ Number of birth } \\
\hline Only one & 84 & 20.6 \\
\hline $2-4$ & 302 & 74 \\
\hline Five and above & 22 & 5.4 \\
\hline \multicolumn{3}{|l|}{ Survival status of the parent } \\
\hline Both parent alive & 378 & 92.6 \\
\hline Parent dead & 30 & 7.4 \\
\hline \multicolumn{3}{|l|}{ HIV status of the father } \\
\hline Positive & 285 & 69.9 \\
\hline Negative & 69 & 16.9 \\
\hline Unknown & 54 & 13.2 \\
\hline
\end{tabular}

The large proportion of mothers (82.3\%) gave birth through spontaneous vaginal delivery without episiotomy (Table 3).

\section{Infant mortality}

Among 408 children followed for a median of 12 months, $35(8.6 \%)$ died. The overall mortality rate was 8.88 (95\% CI: 6.36-12.36) per 100 child-year. Among
Table 2 Socio-demographic and health related characteristics of HIV exposed infants at University of Gondar compressive specialized hospital from July 2013-December 2107

\begin{tabular}{lll}
\hline Characteristic & Number & Percent (\%) \\
\hline Sex of the child & 212 & 52 \\
Male & 196 & 48 \\
Female & & \\
Birth weight & 68 & 16.7 \\
$<2.5 \mathrm{Kg}<\quad<2.5 \mathrm{Kg}$ & 340 & 83.3 \\
$\geq 2.5 \mathrm{Kg}$ & & \\
Gestational age at birth & 370 & 90.7 \\
Term & 38 & 9.3 \\
Preterm & & \\
Growth pattern & 381 & 93.4 \\
Normal & 27 & 6.6 \\
Growth failure & & 95.6 \\
Feeding practice in first 6 months & 390 & 4.4 \\
EBF & 18 & 7.1 \\
Non-EBF & 29 & 92.9 \\
Symptom and sign suggestive of HIV & \\
Yes & 379 & \\
No & & \\
\hline
\end{tabular}

the overall death, more than half were male $(60 \%)$. Nearly half $(45.7 \%)$ of the death occurred between the age of 6 to 12 month (Fig. 1) (Table 4).

\section{Predictors of mortality}

In the bivariable Cox regression analysis, gestational age at birth, growth pattern, marital status of the mother, maternal CD4 cell count at ART initiation, parent survival status, presence of suggestive sign and symptom of HIV infection, infant feeding practice in the first 6-month, and birth weight were associated with infant mortality. However, in multivariable Cox regression analysis, birth weight, presence of suggestive sign and symptom of HIV infection, infant feeding practice in the first 6-month, growth pattern, and parent survival status were statistically significant predictors of child mortality. Based on Cox regression analysis, infants whose weight less than $2.5 \mathrm{Kg}$ at birth was 2.6 (95\% CI: 1.007-6.78) times at high risk of death compared with infants who had a birth weight of $2.5 \mathrm{Kg}$ and above. Infants who had growth failure were 2.9 (95\% CI: 1.09-8.09) times risk for death. Besides, those infants who had a suggestive sign and symptom of HIV infection were 2.9 (95\% CI: 1.33-6.74) fold risk for death compared with their counterparts. 
Table 3 Pregnancy, delivery and other clinical characteristic of HIV positive mothers at University of Gondar compressive specialized hospital from July 2013-December 2017

\begin{tabular}{|c|c|c|}
\hline Characteristics & Number & Percent (\%) \\
\hline \multicolumn{3}{|l|}{ Antenatal care } \\
\hline Attended ANC & 387 & 94.9 \\
\hline No ANC & 21 & 5.1 \\
\hline \multicolumn{3}{|l|}{ Number ANC visit } \\
\hline 1 and 2 & 68 & 17.8 \\
\hline 3 and 4 & 242 & 62.7 \\
\hline 5 and above & 75 & 19.5 \\
\hline \multicolumn{3}{|l|}{ STI screening } \\
\hline Non-reactive & 370 & 90.7 \\
\hline Reactive & 15 & 3.7 \\
\hline Not done & 23 & 5.6 \\
\hline \multicolumn{3}{|l|}{ Place of delivery } \\
\hline Hospital & 364 & 89.2 \\
\hline Health center & 31 & 7.6 \\
\hline Home & 13 & 3.2 \\
\hline \multicolumn{3}{|l|}{ Mode of delivery } \\
\hline SVD & 336 & 82.3 \\
\hline SVD with episiotomy & 15 & 3.7 \\
\hline CS & 57 & 14 \\
\hline \multicolumn{3}{|l|}{ ART starting time } \\
\hline Before this pregnancy & 234 & 57.4 \\
\hline During this pregnancy & 163 & 40 \\
\hline After delivery & 11 & 3 \\
\hline \multicolumn{3}{|l|}{ CD4 cell when ART start } \\
\hline CD4 cell $\leq 350$ & 178 & 43.6 \\
\hline CD4 cell > 350 & 230 & 56.4 \\
\hline \multicolumn{3}{|l|}{ WHO stage when ART start } \\
\hline stage | \& || & 370 & 90.7 \\
\hline Stage III \& IV & 38 & 9.3 \\
\hline
\end{tabular}

Regarding infant feeding practice in the first 6-month of life, being exclusive breastfeeding can reduce infant death by $90 \%$ (AHR $=0.10 ; 95 \%$ CI: $0.037-0.302)$ as compared to those infants on non-exclusive breastfeeding. Besides, those infants lost at least one of their parents by death was 3.3 (95\% CI: 1.503-7.32) times high risk of death when compared with infants whose parent alive (Figs. 2, 3, 4, 5 and 6).

\section{Discussion}

This study showed that the overall infants' mortality rate was 8.88 (95\% CI: 6.36-12.36) per 100 child-year. This result is higher from the study conducted in Pune India (2.4/100-person-year) [10], Malawi (3.4/
100 per person-year) [14], and Zambia (3.5/100 person-years) infants [20]. The exact reason for this difference in mortality is unknown, but it is probably multifactorial. This variation might be due to different follow-up period implemented. The study in India took 12 months' follow-up period and 70 days a study in Zambia. The difference in the study population is another source; in Malawi only infants up to 48 weeks of age were included. Other possible explanation might be a high burden of infection [21], childhood illness [22], low coverage of prophylaxis [23, 24], high prevalence of under-nutrition $[25,26]$, low coverage of immunization [27], mixed feeding practice, pre-lacteal feeding [28], low infrastructure [29], health care facilities related infection [30], poor-bottle feeding hygiene recorded in Ethiopia, particularly in the current study region ( [31]. The expansion of ART initiation during delivery remains a national health priority. Hence, asymptomatic infections are remaining undiagnosed and not managed that increased probability of death.

In the Cox multivariable regression analysis parent death was a 3-fold risk for their child death among HIV exposed infants compared with those infants' with parent alive. The evidence was supported by other studies from Zimbabwe [17] and a systemic review of HIV exposed uninfected African infant [9]. In Ethiopia, Orphan problems are universal. These children are subjected to abuse, neglect exploitation, and carelessness to bring to health institution early and/or to provide medication as ordered [32]. This is because those infants who lost their mother, father or both would lack quality of care and support, which might expose the child to the nutritional insecurity that leads to growth and development failure and undernutrition. Undernourished children could be vulnerable to infectious disease [33] and it increases the death of infants.

This study showed that infants who were on nonexclusive breastfeeding had at higher risk of death compared with infants on exclusive breastfeeding. This finding supported by studies from Cameron [13], a systemic review of HIV exposed infant studies [31], Zambia [20] and Uganda [12]. Mixed feeding, short duration of breastfeeding, and cessation of breastfeeding predisposes infants to dietary pathogens, diarrhea, and declined immunity [11]. As a result, infant mortality can be occurred more likely.

Infants with low birth weight were at high risk for death compared with infants who have normal birth weight. Finding in Malawi [14] also showed that low birth weight increases child mortality. In Ethiopia, the burden of low birth weight is one of the main problems, $17.3 \%$ newborn are below normal birth weight [34]. It exposed the infant to hypoglycemia, hypothermia, mental retardation, and growth failure 


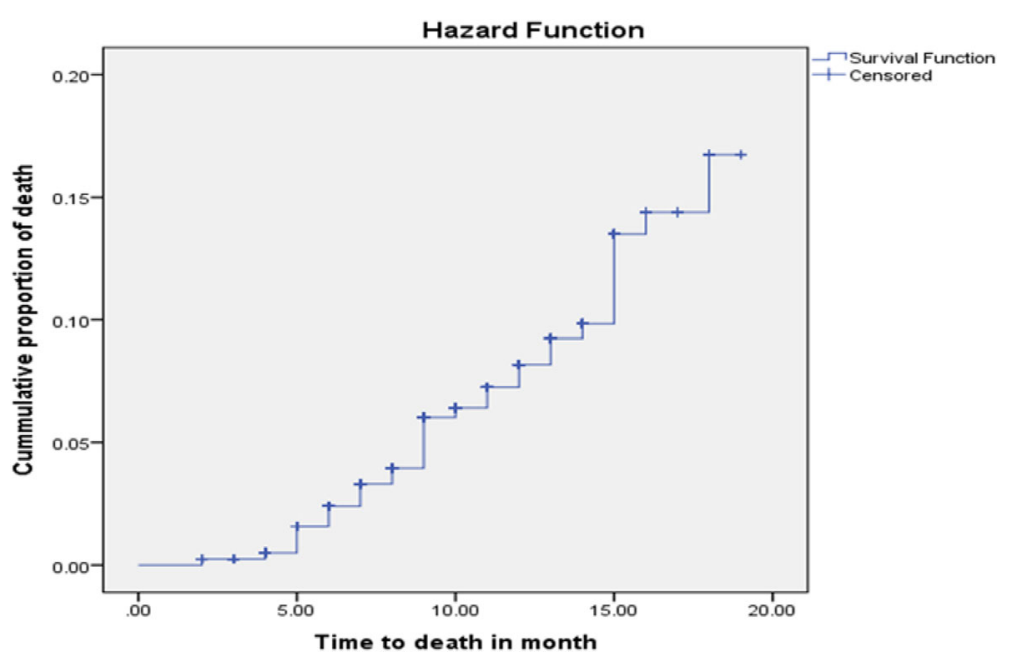

Fig. 1 Kaplan-Meier curve of mortality proportion for HIV exposed infants at University of Gondar Comprehensive Specialized Hospital, Northwest Ethiopia, and July 2013-December 2017

Table 4 Bivariable and multivariable cox regression analysis of predictors of mortality among HIV exposed infants at University of Gondar Comprehensive Specialized Hospital, Northwest Ethiopia, July 2013 December 2017

\begin{tabular}{|c|c|c|c|c|}
\hline Characteristics & Death & Censored & CHR (95\% Cl) & AHR $(95 \% \mathrm{Cl}) \mathrm{P}$ \\
\hline \multicolumn{5}{|l|}{ Marital status of mother } \\
\hline Married & 18 & 278 & 1 & 1 \\
\hline Unmarried & 17 & 95 & $2.43(1.25-4.711)$ & $0.96(0.45-2.06) 0.9$ \\
\hline \multicolumn{5}{|l|}{ Gestational age at birth } \\
\hline Term & 22 & 348 & 1 & 1 \\
\hline Preterm & 13 & 25 & $5.93(2.98-11.77)$ & $1.65(0.64-4.22) 0.29$ \\
\hline \multicolumn{5}{|c|}{ Feeding practice in the first 6 month } \\
\hline EBF & 29 & 361 & 1 & 1 \\
\hline Non-EBF & 6 & 12 & $9.4(3.85-22.96)$ & $0.10(0.037-0.302)<0.0001$ \\
\hline \multicolumn{5}{|l|}{ Parent survival status } \\
\hline Both alive & 23 & 355 & 1 & 1 \\
\hline At least one of dead & 12 & 18 & $7.28(3.6214 .63)$ & $3.32(1.5-7.32) 0.003$ \\
\hline \multicolumn{5}{|l|}{ Growth pattern } \\
\hline Normal & 29 & 352 & 1 & 1 \\
\hline Growth failure & 6 & 21 & $3.95(1.64-9.54)$ & $2.97(1.09-8.09) 0.03$ \\
\hline \multicolumn{5}{|c|}{ Symptom and sign suggestive of HIV } \\
\hline Yes & 13 & 16 & $8.034(4.042-15.98$ & 2.99 (1.33-6.71) 0.008 \\
\hline No & 22 & 357 & 1 & 1 \\
\hline \multicolumn{5}{|l|}{ Birth weight } \\
\hline$<2.5 \mathrm{Kg}$ & 17 & 51 & $0.203(0.105-0.394)$ & 2.6 (1.007-6.78) 0.04 \\
\hline$\geq 2.5 \mathrm{Kg}$ & 18 & 322 & 1 & 1 \\
\hline \multicolumn{5}{|l|}{ CD4 cell when ART start } \\
\hline CD4 cell $\leq 350$ & 22 & 156 & $2.24(1.13-4.44)$ & $0.049(0.226-1.064) 0.07$ \\
\hline CD4 cell > 350 & 13 & 217 & 1 & 1 \\
\hline
\end{tabular}




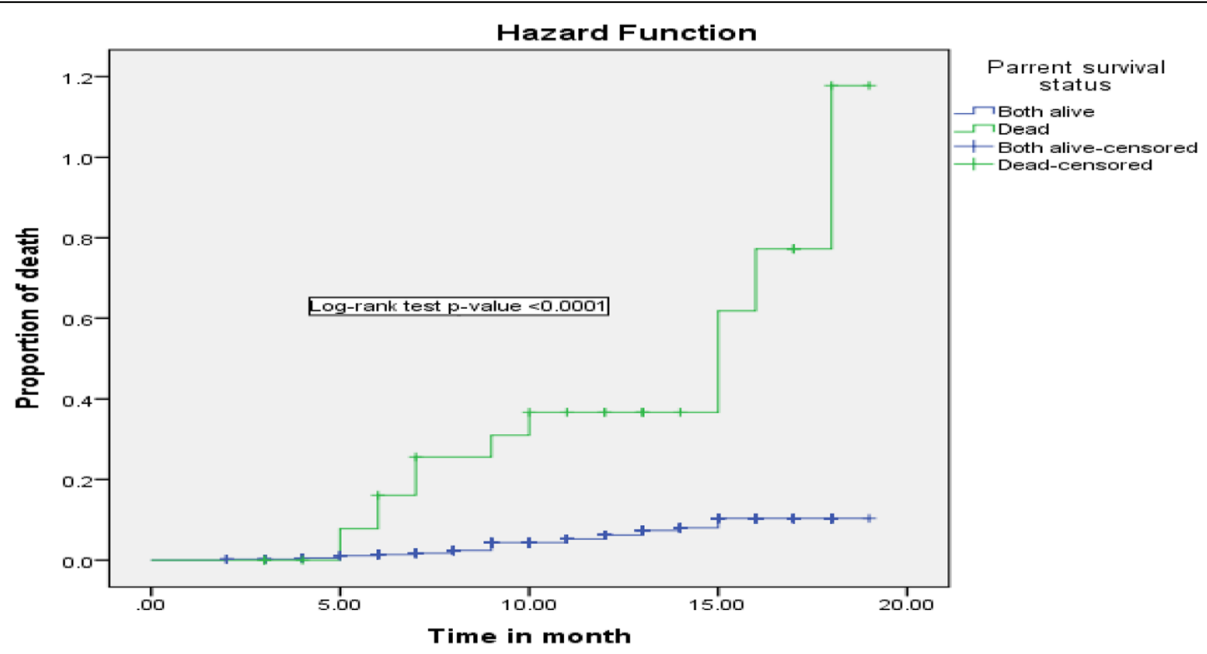

Fig. 2 Kaplan-Meier curve of mortality estimate for parent survival status among HIV exposed infants at University of Gondar Comprehensive Specialized Hospital, Northwest Ethiopia, July 2013-December 2017

that exposed to infection and related complication, which further contribute to child mortality.

In this study presence of the suggestive sign and symptom of HIV, infection was one of the predictors of infant mortality. The result was supported by a systemic review on HIV-exposed uninfected African child [9] and a study in Botswana [35]. This may be due to HIV exposed infants are expected to impaired immunity system than HIV unexposed infants. This sign and symptoms are the indications of underdiagnosed and non-managed systemic infections. As infection rate increase the risk of death is high.

Growth failure was one of the predictors of infant mortality which increases the death rate of infants by 2.9 times compared with infants who had normal growth. This evidence was supported by a systemic review conducted on HIV exposed uninfected infant [25]. This may be due to the reason that those infant with growth failure can expose to infection, immunological failure, and increased hospitalization that could increase mortality of infants.

\section{Limitation of the study}

Most of the limitations of the study related with poor documentation system. This study did not show the exact cause of death because of poor recorded patient data; in the chart, it was difficult to access the cause

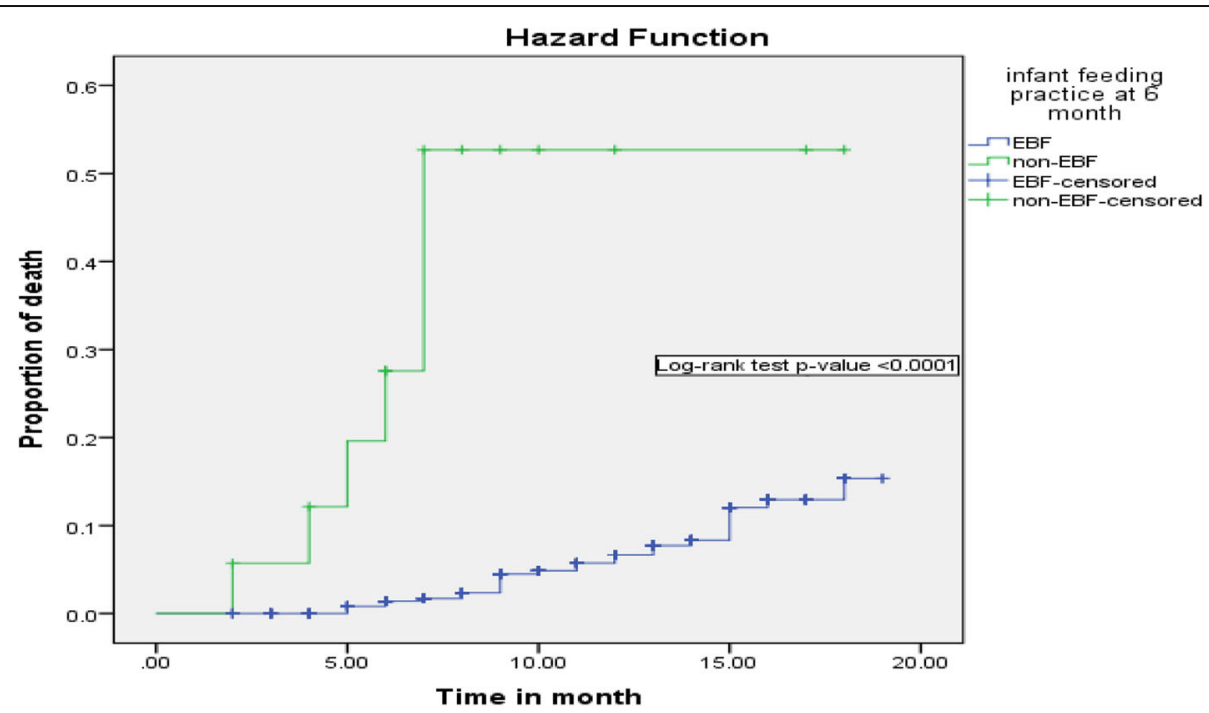

Fig. 3 Kaplan-Meier curve of mortality estimate for infant feeding practice among HIV exposed infants at University of Gondar Comprehensive Specialized Hospital, Northwest Ethiopia, July 2013-December 2017 


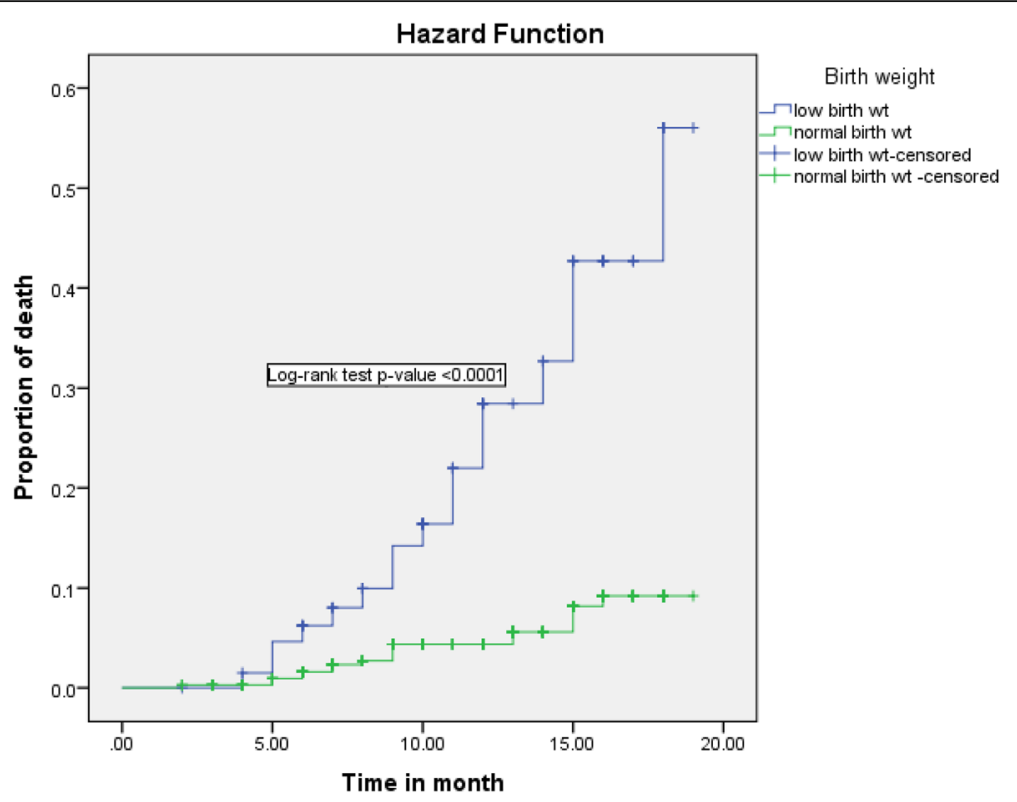

Fig. 4 Kaplan-Meier curve of mortality estimate for birth weight among HIV exposed infants at University of Gondar Comprehensive Specialized Hospital, Northwest Ethiopia, July 2013-December 2017

of death for the infants. The study conducted based on registered data; we could not include some variables like immunization status, family income and hospitalization rate in the analysis. The other limitation of this study, it did not have a comparison group from HIV unexposed infants to see the clear contribution of HIV exposure on infant mortality.

\section{Conclusions and recommendation}

Mortality of HIV exposed infants was high in Ethiopia. Prevention of the occurrence of HIV infection symptom, growth failure, and low birth weight is essential and further treat early whenever they occurred. Still, behavioral change interventions on mother who practice non-exclusive breastfeeding are

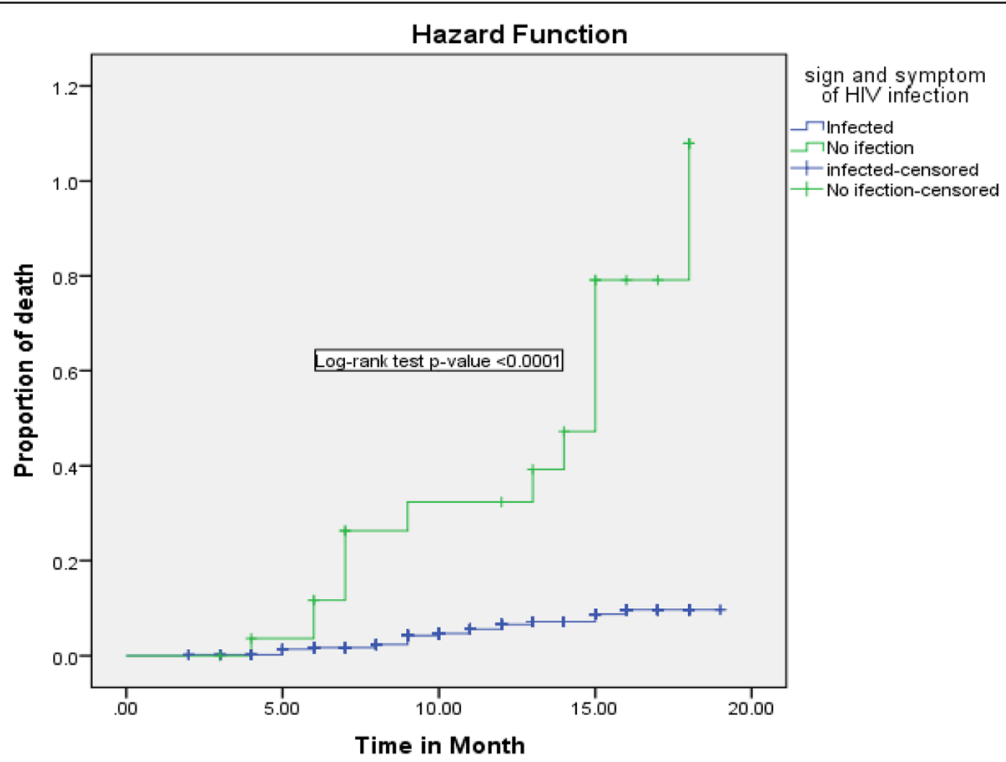

Fig. 5 Kaplan-Meier curve of mortality estimate for suggestive sign and symptom of HIV infection among HIV exposed infants at University of Gondar Comprehensive Specialized Hospital, Northwest Ethiopia, July 2013-December 2017 


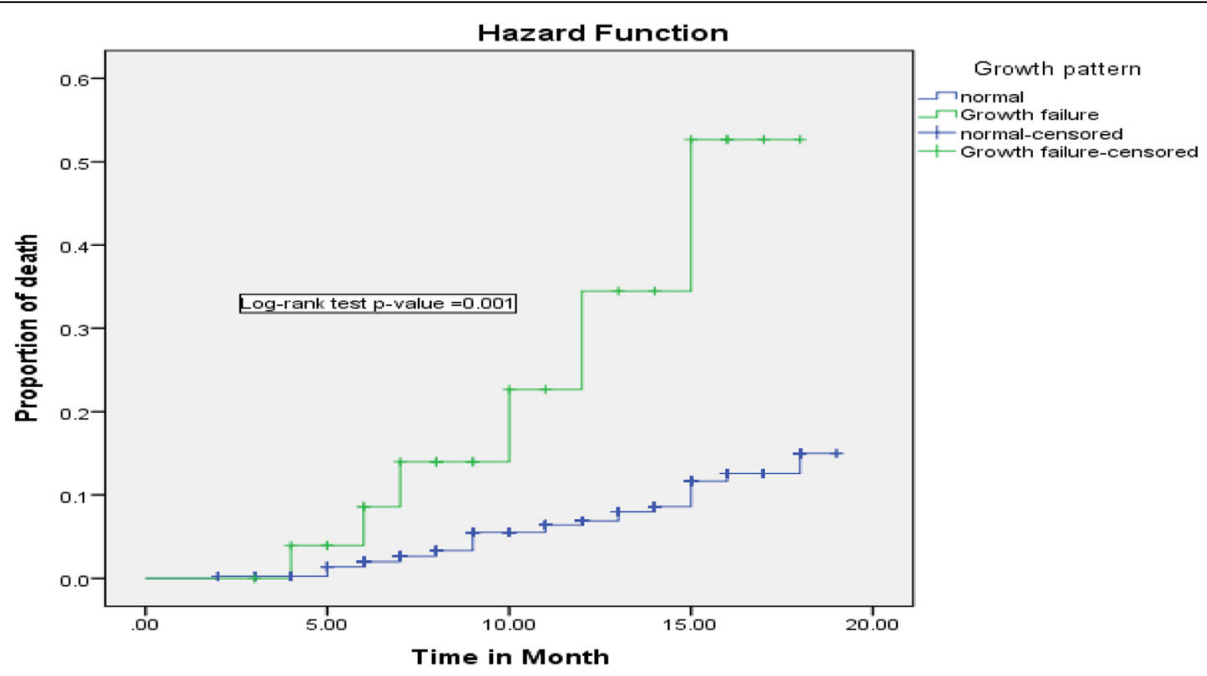

Fig. 6 Kaplan-Meier curve of mortality estimate for growth pattern among HIV exposed infants at University of Gondar Comprehensive Specialized Hospital, Northwest Ethiopia, July 2013-December 2017

indicated. Especial care for orphan infants is required due to their nature of vulnerability to varieties of health problem. It would be good to fill all the data properly on the chart, registration book and followup forms, like immunization status, income, and hospitalization rate of the child.

\section{Abbreviations \\ AHR: Adjusted Hazard Ratio; AIDS: Acquired Immune Deficiency Syndrome; ANC: Antenatal Care; ART: Antiretroviral Therapy; CD4: Cluster of Differentiation 4; CHR: Crude Hazard Ratio; Cl: Confidence Interval; DNA: Deoxyribonucleic Acid; EBF: Exclusive Breast Feeding; HIV: Human Immunodeficiency Virus; PCR: Polymerase Chain Reaction; PMTCT: Prevention of Mother-to-Child Transmission; STI: Sexual Transmitted Infection; UN IGME: United Nations Inter-Agency Group for Child Mortality Estimation; UNAIDS: Joint United Nations Program on HIV/AIDS; WHO: World Health Organization}

\section{Acknowledgments}

The authors acknowledge the University of Gondar.

\section{Authors' contributions}

CAW conceived and designed the study and preparing the manuscript. AE review and provide constructive feedback in the designing phase of the study, involve in the analysis and review the manuscript. NBT review, write the discussion part, review and approve the final draft of the manuscript. All the authors read the manuscript before they have given the final approval for publication.

\section{Funding}

Financial support was obtained from University of Gondar for data collection.

\section{Availability of data and materials}

All data generated or analyzed during this study are included in this article.

\section{Ethics approval and consent to participate}

Ethical clearance was obtained from University of Gondar ethical review committee. Consent was not applicable because we use recorded data.

\section{Consent for publication}

Not applicable

\section{Competing interests}

The authors declared no competing interests.

\section{Author details}

${ }^{1}$ Department of Pediatrics and Child Health Nursing, School of Nursing, College of Medicine and Health Science, University of Gondar, Gondar, Ethiopia. ${ }^{2}$ Department of Pediatrics and Child Health Nursing, College of Medicine and Health Science, Bahir Dar University, Bahir Dar, Ethiopia. ${ }^{3}$ Unit of Community Health Nursing, School of Nursing, College of Medicine and Health Science, University of Gondar, P.O.BOX=196, Gondar, Ethiopia.

Received: 11 June 2019 Accepted: 23 October 2019

Published online: 07 November 2019

\section{References}

1. UNAIDS. UNAIDS 2017 estimates. 2019

2. Joint United Nations Programme on HIV/AIDS. Global Plan towards the elimination of new HIV infections among children by 2015 and keeping their mothers alive 2016.

3. UNAIDS. How AIDS changed everything. MDG 6: 15 years, 15 lessons of hope from the AIDS response, 2014. Geneva: 2014.

4. UNAIDS. On the Fast-Track to AIDS Free Generation. 2016.

5. United Nations Inter-agency Group for Child Mortality Estimation (UN IGME). Levels and Trends in Child Mortality. New York: United Nations Children's Fund; 2017.

6. Ethiopian Federal Ministry of Health. Comprehensive Integrated National PMTCT/MNCH/SRH, Guideline. Adiss Abeba 2014.

7. Koye DN, Zeleke BM. Mother-to-child transmission of HIV and its predictors among HIV-exposed infants at a PMTCT clinic in Northwest Ethiopia. BMC Public Health. 2013;13(1):398

8. Ethiopian Federal ministry of health. $<$ Consolidated Training material Aug 18,2017 (3).pdf>. Addis Abeba 2017.

9. Afran L, Garcia Knight M, Nduati E, Urban BC, Heyderman RS, RowlandJones SL. HIV-exposed uninfected children: a growing population with a vulnerable immune system? Clin Exp Immunol. 2014;176(1):11-22.

10. Singh HK, Gupte N, Kinikar A, Bharadwaj R, Sastry J, Suryavanshi N, et al. High rates of all-cause and gastroenteritis-related hospitalization morbidity and mortality among HIV-exposed Indian infants. BMC Infect Dis. 2011;11:193.

11. Kurewa E, Gumbo F, Munjoma M, Mapingure M, Chirenje M, Rusakaniko S, et al. Effect of maternal HIV status on infant mortality: evidence from a 9month follow-up of mothers and their infants in Zimbabwe. J Perinatol. 2010;30(2):88-92.

12. Munyagwa M, Baisley K, Levin J, Brian M, Grosskurth H, Maher D. Mortality of HIV-infected and uninfected children in a longitudinal cohort in rural 
south-West Uganda during 8 years of follow-up. Tropical Med Int Health. 2012:17(7):836-43.

13. Boerma RS, Wit FWNM, Orock SO, Schonenberg-Meinema D, Hartdorff CM, Bakia A, et al. Mortality risk factors among HIV-exposed infants in rural and urban Cameroon. Tropical Med Int Health. 2015;20(2):170-6.

14. Taha TE, Dadabhai SS, Sun J, Rahman MH, Kumwenda J, Kumwenda N Child mortality levels and trends by HIV status in Blantyre, Malawi. JAIDS J Acquir Immune Defic Syndr. 2012;61(2):226-34.

15. Gill MM, Hoffman HJ, Ndatimana D, Mugwaneza P, Guay L, Ndayisaba GF, et al. 24-month HIV-free survival among infants born to HIV-positive women enrolled in option B+ program in Kigali, Rwanda: The Kabeho Study Medicine 2017;96(51):e9445.

16. Wagner A, Slyker J, Langat A, Inwani I, Adhiambo J, Benki-Nugent S, et al. High mortality in HIV-infected children diagnosed in hospital underscores need for faster diagnostic turnaround time in prevention of mother-to-child transmission of HIV (PMTCT) programs. BMC Pediatrics. 2015;15(1). https:// doi.org/10.1186/s12887-015-0325-8.

17. Marinda E, Humphrey JH, lliff PJ, Mutasa K, Nathoo KJ, Piwoz EG, et al. Child mortality according to maternal and infant HIV status in Zimbabwe. Pediatr Infect Dis J. 2007;26(6):519-26.

18. Villamor E, Misegades L, Fataki MR, Mbise RL, Fawzi WW. Child mortality in relation to HIV infection, nutritional status, and socio-economic background. Int J Epidemiol. 2005;34(1):61-8.

19. Nakiyingi JS, Bracher M, Whitworth JA, Ruberantwari A, Busingye J, Mbulaiteye SM, et al. Child survival in relation to mother's HIV infection and survival: evidence from a Ugandan cohort study. Aids. 2003;17(12):1827-34.

20. Kuhn L, Aldrovandi GM, Sinkala M, Kankasa C, Semrau K, Mwiya M, et al. Effects of early, abrupt weaning on HIV-free survival of children in Zambia. N Engl J Med. 2008;359(2):130-41.

21. Seale AC, Mwaniki M, Newton CR, Berkley JA. Maternal and early onset neonatal bacterial sepsis: burden and strategies for prevention in subSaharan Africa. Lancet Infect Dis. 2009:9(7):428-38.

22. Walker CLF, Rudan I, Liu L, Nair H, Theodoratou E, Bhutta ZA, et al. Global burden of childhood pneumonia and diarrhoea. Lancet. 2013; 381(9875):1405-16.

23. Wudineh F, Damtew B. Mother-to-child transmission of HIV infection and its determinants among exposed infants on care and follow-up in Dire Dawa City, eastern Ethiopia. AIDS Res Treatment. 2016:2016.

24. Koye DN, Ayele TA, Zeleke BM. Predictors of mortality among children on antiretroviral therapy at a referral hospital, Northwest Ethiopia: a retrospective follow up study. BMC Pediatr. 2012;12(1):161.

25. Demissie $S$, Worku A. Magnitude and factors associated with malnutrition in children 6-59 months of age in pastoral community of Dollo ado district, Somali region. Ethiopia Sci J Public Health. 2013;1 (4):175-83.

26. Derebe G, Biadgilign S, Trivelli M, Hundessa G, Robi ZD, Gebre-Mariam M, et al. Determinant and outcome of early diagnosis of HIV infection among HIVexposed infants in Southwest Ethiopia. BMC research notes. 2014;7(1):309.

27. Kassahun MB, Biks GA, Teferra AS. Level of immunization coverage and associated factors among children aged 12-23 months in lay Armachiho District, North Gondar zone, Northwest Ethiopia: a community based cross sectional study. BMC research notes. 2015;8(1):239.

28. Shumey A, Demissie M, Berhane $Y$. Timely initiation of complementary feeding and associated factors among children aged 6 to 12 months in northern Ethiopia: an institution-based cross-sectional study. BMC Public Health. 2013:13(1):1050.

29. Shiferaw A, Söderbom M, Siba E, Alemu G. Road infrastructure and enterprise dynamics in Ethiopia. J Dev Stud. 2015;51(11):1541-58.

30. Allegranzi B, Nejad SB, Combescure C, Graafmans W, Attar H, Donaldson $L$, et al. Burden of endemic health-care-associated infection in developing countries: systematic review and meta-analysis. Lancet. 2011:377(9761):228-41.

31. Muluye D, Woldeyohannes D, Gizachew M, Tiruneh M. Infant feeding practice and associated factors of HIV positive mothers attending prevention of mother to child transmission and antiretroviral therapy clinics in Gondar town health institutions, Northwest Ethiopia. BMC Public Health. 2012;12(1):240

32. Nayak BK. Orphan problems and community concern in Ethiopia. Int $J$ Manag Soc Sci Res. 2014;3:8-15.

33. Bain $L E$, Awah PK, Geraldine N, Kindong NP, Siga Y, Bernard N, et al. Malnutrition in Sub-Saharan Africa: burden, causes and prospects. Pan Afr Med J. 2013;15(1). https://doi.org/10.11604/pamj.2013.15.120.2535.
34. Endalamaw A, Engeda EH, Ekubagewargies DT, Belay GM, Tefera MA. Low birth weight and its associated factors in Ethiopia: a systematic review and meta-analysis. Ital J Pediatr. 2018;44(1):141.

35. Shapiro RL, Lockman S, Kim S, Smeaton L, Rahkola JT, Thior I, et al. Infant morbidity, mortality, and breast milk immunologic profiles among breastfeeding HIV-infected and HIV-uninfected women in Botswana. J Infect Dis. 2007;196(4):562-9.

\section{Publisher's Note}

Springer Nature remains neutral with regard to jurisdictional claims in published maps and institutional affiliations.

\section{Ready to submit your research? Choose BMC and benefit from:}

- fast, convenient online submission

- thorough peer review by experienced researchers in your field

- rapid publication on acceptance

- support for research data, including large and complex data types

- gold Open Access which fosters wider collaboration and increased citations

- maximum visibility for your research: over $100 \mathrm{M}$ website views per year

At BMC, research is always in progress.

Learn more biomedcentral.com/submissions 